\title{
PATTERN OF CHROMOSOMAL ANOMALIES IN DYSMORPHIC CHILDREN AND THEIR CLINICAL CORRELATION
}

\author{
V. Booma ${ }^{1}$, B. Mohamed Ansar Ali ${ }^{2}$ \\ ${ }^{1}$ Associate Professor, Department of Paediatrics, Coimbatore Medical College \& Hospital, Coimbatore \\ ${ }^{2}$ Assistant Professor, Department of Paediatrics, Coimbatore Medical College \& Hospital, Coimbatore.
}

\section{BACKGROUND}

ABSTRACT

Chromosomal abnormalities are an important cause of congenital anomalies.

\section{OBJECTIVE}

To evaluate the pattern of chromosomal imbalances in congenital anomaly child and to find out the frequency of internal anomalies associated with external anomalies.

\section{METHOD}

A total of 75 individuals in different age groups presenting clinical profile like syndromic features, congenital anomalies and facial dysmorphism were taken. All patients underwent clinical assessment, chest x-ray, echocardiogram and cytogenetic assessment through karyotyping. Chi-square test was used in the statistical analysis.

\section{RESULTS}

Out of 75 patients $40 \%$ are males, $60 \%$ are females of which chromosomal abnormalities detected 30\% and 35\% respectively; $62.66 \%$ have minor anomalies and major anomalies of 37.33\%. Chromosomal abnormality detected includes Down's syndrome (77.77\%), satellite 13 and 22(11.11\%), turners syndrome (5.55\%), trisomy 19(5.55\%). Most common internal anomaly is congenital heart disease, predominantly atrioventricular septal defect. It has statistical significance with consanguinity $(p<0.05)$.

\section{CONCLUSION}

Frequency of Down's syndrome is high, reflecting the need of screening in all antenatal women. Karyotyping is recommended in all dysmorphic children as it can bring to the diagnosis, treatment and prognosis and for genetic counselling of patients and families.

\section{KEYWORDS}

Karyotyping, Chromosomal Imbalances, Congenital Anomaly.

HOW TO CITE THIS ARTICLE: V. Booma, B. Mohamed Ansar Ali. "Pattern of Chromosomal Anomalies in Dysmorphic Children and their Clinical Correlation." Journal of Evolution of Medical and Dental Sciences 2015; Vol. 4, Issue 101, December 17;

Page: 16622-16628, DOI: $10.14260 /$ jemds/2015/2480

\section{INTRODUCTION}

\section{AIMS AND OBJECTIVES}

The aim of my dissertation is highlighting the association between major and minor congenital anomalies with chromosomal abnormalities. Chromosomal aberrations are common causes of multiple anomaly syndromes. Babies admitted with major and minor congenital anomalies, markers of chromosomal abnormalities were subjected to karyotyping (G-banding) study. Venous blood is collected for this study. The study also analyse for any association between chromosomal imbalances and phenotypic expression and to correlate the severe congenital anomalies with chromosomal imbalances to identify whether the anomaly is sporadic or,

Financial or Other, Competing Interest: None.

Submission 23-10-2015, Peer Review 24-10-2015,

Acceptance 13-11-2015, Published 16-12-2015.

Corresponding Author:

Dr. V. Booma,

46,50 Feet Road,

Krishnaswamy Nagar,

Ramanathapuram,

Coimbatore-641045.

E-mail: boomavmohan@yahoo.co.in

DOI:10.14260/jemds/2015/2480 hereditary and also tries to find the various congenital anomalies, their sex difference and to identify correlation between maternal age consanguinity, family history and antenatal risk factors for congenital anomaly. This is the first this kind of study in this region and serves as an eye-opener for further study.

\section{OBJECTIVES OF THE STUDY}

\section{Primary Objective}

To evaluate the pattern of chromosomal imbalances in a child with congenital anomaly.

\section{Secondary Objective}

To find out the frequency of internal anomalies associated with external anomalies and to correlate it with karyotyping.

To correlate chromosomal anomalies with maternal age, consanguinity, antenatal risk factors, etc.

To find out the anomalies and chromosomal imbalances correlate its severity of clinical illness.

\section{METHODOLOGY \\ - Study Design \\ - Descriptive study.}




\section{- $\quad$ Study Place}

Department of Pediatrics, Coimbatore Medical College and Hospital (CMCH).

- $\quad$ Study Period Oct 2012- Oct 2013.

\section{- $\quad$ Study Population}

Includes dysmorphic children are attending to the Department of Pediatrics, OPD and also admitted in Pediatric ward and NICU at Coimbatore Medical College Hospital who satisfy the inclusion criteria.

\section{Inclusion Criteria}

- Children with major and minor external congenital anomalies.

- Children with dysmorphic features suggestive of chromosomal anomalies.

\section{Exclusion Criteria}

- $\quad$ Pre-term with isolated PDA.

- Still born with congenital anomaly.

\section{Sample Size: 75}

This formula is the one used by Krejcie and Morgan in their 1970 article "Determining Sample Size for Research Activities" (Educational and Psychological Measurement, \#30, pp. 607610).

\section{Sampling Technique}

All children and neonates fulfilling inclusion criteria were included after obtaining consent from the parents until sample size was achieved.

\section{Definitions}

- According to the World Health Organization (WHO) document of 1972, the term congenital malformations should be confined to structural defects at birth. ${ }^{1}$

- Malformations were divided into major and minor; major malformation interferes considerably with the function of the child, minor malformation gives no serious medical or cosmetic consequences to the patients. ${ }^{1}$

- Major congenital anomalies include CNS malformations, CVS malformations, musculoskeletal, gastrointestinal and genitourinary malformations. ${ }^{1}$

- Chromosome analysis technic: GTG banding.

\section{MANEUVER}

Babies and children who are satisfying the inclusive criteria are taken for the study. Informed consent were obtained from the parents. Relevant data including age, sex, maternal age, paternal age, consanguinity, antenatal risk factors, similar family history and external anomalies detected were entered in the preformed proforma. Then the child was subjected to the study by doing chest x-ray, ultrasound abdomen in the Department of Radiology, $\mathrm{CMCH}$ and echocardiography in the Department of Cardiology, CMCH. Later $3 \mathrm{ml}$ of blood sample was collected in heparin coated vaccutainer and was taken to the Cytogenetic Lab, Department of Zoology in Bharathiar University within 3 hours and analysed for chromosomal study (CGC banding).

\section{RESULTS}

A total of 75 children with external anomalies were included in the study. Out of 75 children, $30(40 \%)$ are males and $45(60 \%)$ are females. Most of the children (66.66\%) are coming under 1 year of age. Among the congenital anomaly children, $30 \%$ of males and $35 \%$ of females are having chromosomal anomalies. In our study mild predominance among girls is observed; $47(62.66 \%)$ children have major anomalies and $28(37.33 \%)$ children have major anomalies.

Among the external anomalies, the most common is Down's features followed by central nervous system anomalies, limb anomalies, cleft lip/palate, Turner features. Among the internal anomalies, most common is congenital heart disease (22 cases) followed by tracheo-esophageal fistula (2 cases), renal anomaly occurs. Among the chromosomal abnormalities, trisomy 21 is the most common (14 cases) out of which 2 are having mosaic pattern. Other chromosomal abnormalities detected are one satellite 13, one case of satellite 22, one trisomy 19 and one Turner's syndrome.

The data obtained were analysed in SPSS version 16 software as follows

1. Features of study population (Age, sex).

2. Percentage of major and minor anomalies.

3. Pattern of external anomaly in study population.

4. Pattern of internal anomaly in study population.

5. Pattern of chromosomal anomalies in study population.

6. Maternal age with congenital anomaly and their correlation with age.

7. Distribution of paternal age.

8. Correlation of consanguinity with congenital anomaly.

9. Correlation of antenatal risk factor with congenital anomaly.

10. Correlation of family history with congenital anomaly.

11. Pattern of congenital heart disease in Down's syndrome cases.

\section{DESCRIPTIVE ANALYSIS}

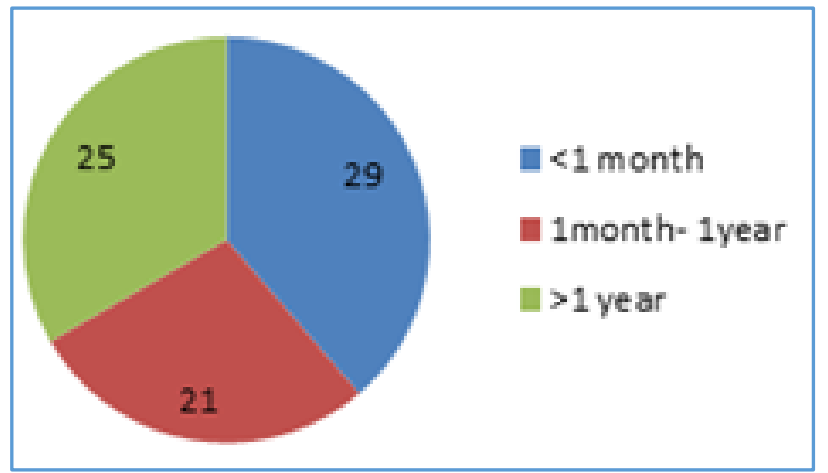

Distribution of Age in Study Population

\begin{tabular}{|c|c|c|c|}
\hline $\begin{array}{c}\text { Chi-Square } \\
\text { Tests }\end{array}$ & Value & df & $\begin{array}{c}\text { Asymp. Sig. } \\
\text { (2-sided) }\end{array}$ \\
\hline $\begin{array}{c}\text { Pearson Chi- } \\
\text { Square }\end{array}$ & $4.073 \mathrm{E} 2^{\mathrm{a}}$ & 380 & .04 \\
\hline Likelihood Ratio & 139.043 & 380 & .01 \\
\hline N of Valid Cases & 100 & & \\
\hline
\end{tabular}




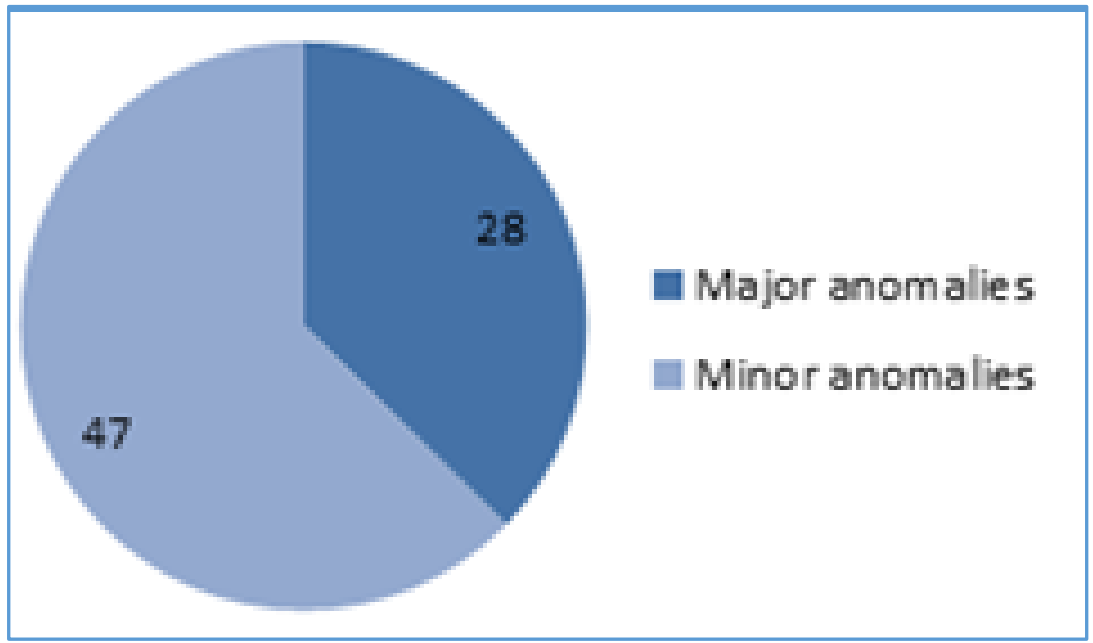

Distribution of Major and Minor Anomaly Study Population

\begin{tabular}{|c|c|c|c|c|}
\hline External Anomaly & Frequency & Male & Female & Cumulative Percent \\
\hline Down's features & 26 & 10 & 16 & 34.66 \\
\hline Turner's features & 3 & - & 3 & 4 \\
\hline Edward features & 2 & 1 & 1 & 2.6 \\
\hline Cleft lip/palate & 6 & 4 & 2 & 8 \\
\hline Limb anomalies & 6 & 5 & 1 & 2.6 \\
\hline Choanal atresia & 2 & 2 & & 6.6 \\
\hline High arched palate & 5 & 2 & 3 & 1.3 \\
\hline Accessory auricle & 1 & & 1 & 10.6 \\
\hline Marfan features & 3 & & 3 & 2.6 \\
\hline Neural tube defects & 8 & 4 & 4 & 1.3 \\
\hline $\begin{array}{c}\text { Congenital } \\
\text { hydrocephalus }\end{array}$ & 2 & & 2 & 4 \\
\hline Primary microcephaly & 5 & 2 & 3 & 1.3 \\
\hline Mucopolysaccharidosis & 1 & 1 & & 2 \\
\hline Anal atresia & 3 & 1 & 1 & \\
\hline Pierre robin features & 1 & 1 & & \\
\hline Absent right auricle & 1 & 1 & \\
\hline \multicolumn{2}{|l|}{ Pattern of External Anomalies in Study Population } \\
\hline
\end{tabular}

\begin{tabular}{|c|c|c|c|}
\hline Likelihood Ratio & 139.043 & 380 & .01 \\
\hline N of Valid Cases & 100 & & \\
\hline
\end{tabular}

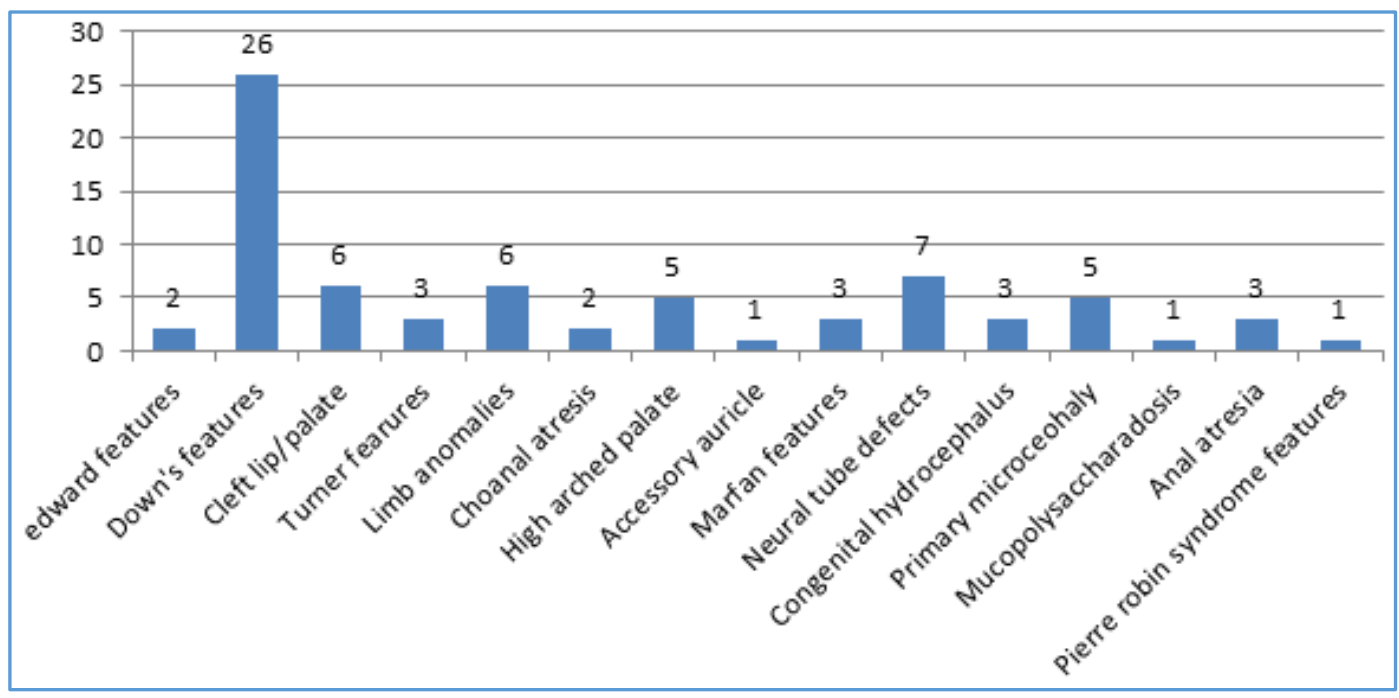

From the above table, we infer that the p-value is less than the level of significant (i.e. 0.05), so we accept our hypothesis hence we concluded that karyotyping and external anomaly are associated. 
Distribution of chromosomal anomalies in study population:

\begin{tabular}{|c|c|c|}
\hline $\begin{array}{c}\text { Chromosomal } \\
\text { Anomalies }\end{array}$ & Frequency & Percent \\
\hline Trisomy 21 & 12 & 66.66 \\
\hline Trisomy mosaic 21 & 2 & 11.11 \\
\hline $45+\mathrm{X} 0$ & 1 & 5.55 \\
\hline Trisomy 19 & 1 & 5.55 \\
\hline Satellite & 2 & 11.11 \\
\hline
\end{tabular}

\begin{tabular}{|c|c|c|}
\hline Maternal Age & Frequency & Cumulative Percent \\
\hline$<20$ year & 11 & 14.66 \\
\hline $20-25$ years & 48 & 64 \\
\hline$>25$ years & 16 & 21.33 \\
\hline
\end{tabular}

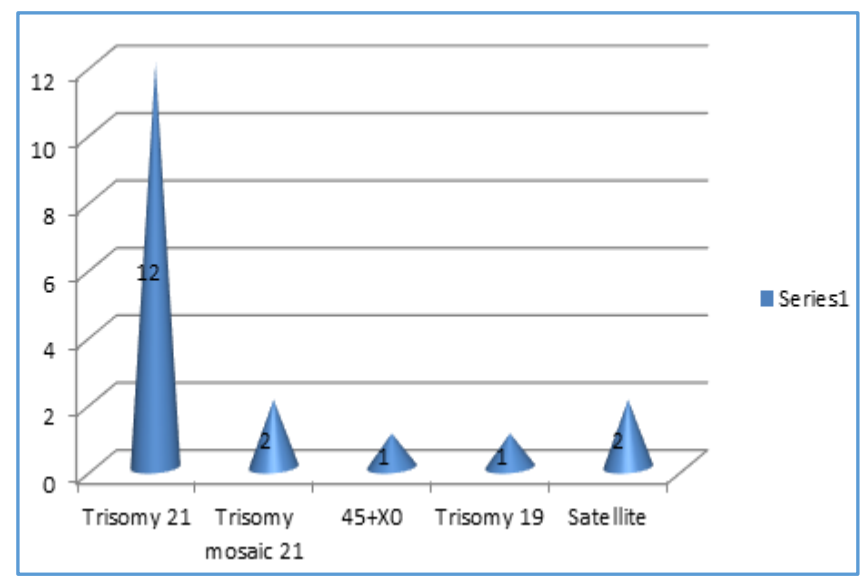

Distribution of maternal age among congenital anomalies

\begin{tabular}{|c|c|c|}
\hline Maternal Age & Frequency & Cumulative Percent \\
\hline$<20$ year & 11 & 14.66 \\
\hline $20-25$ years & 48 & 64 \\
\hline$>25$ years & 16 & 21.33 \\
\hline
\end{tabular}

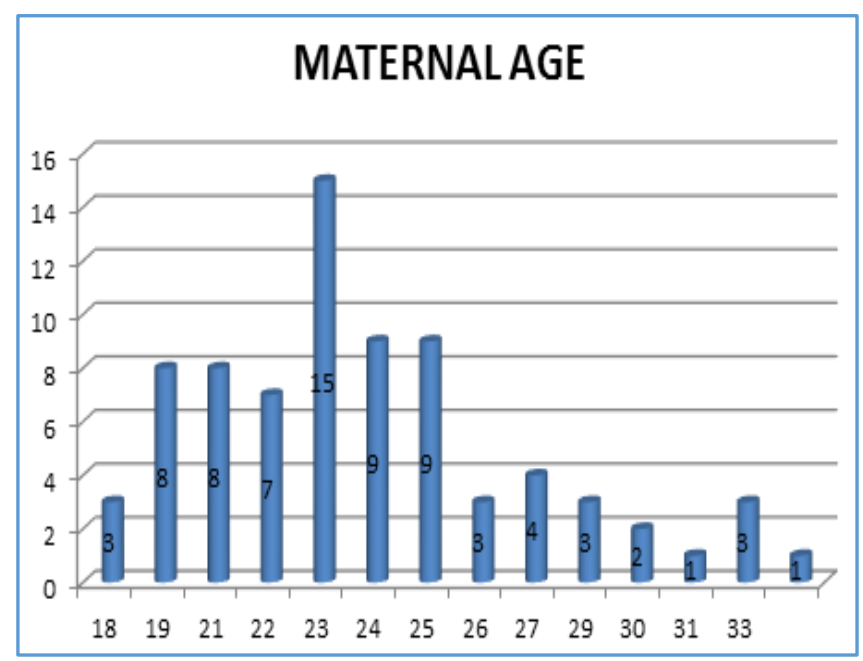

Distribution of maternal age in Down's syndrome patients Comparison of maternal age among Down's syndrome cases are as follows: Among the 14 cases, one child was from orphanage whose parent's details are not known. Among the other children, 4 had the maternal age more than 25 and one had less than 20 .

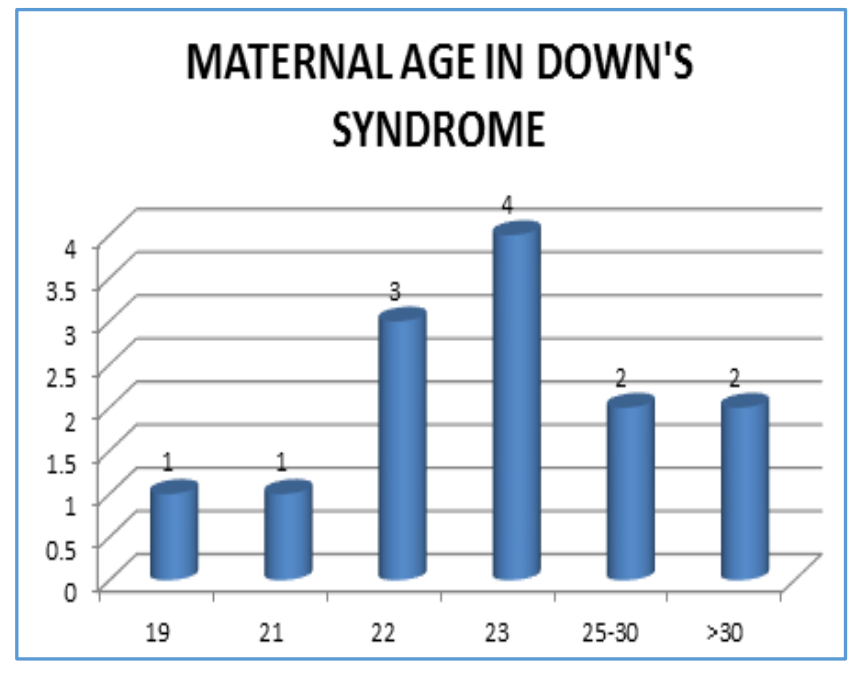

\begin{tabular}{|c|c|c|}
\hline Maternal Age & Frequency & Cumulative Percent \\
\hline$<20$ year & 1 & 7.6 \\
\hline 20-25 years & 8 & 61.53 \\
\hline 26-30 years & 2 & 15.38 \\
\hline$>30$ years & 2 & 15.38 \\
\hline
\end{tabular}

Correlation of consanguinity with congenital anomalies

\begin{tabular}{|c|c|c|c|}
\hline Chi-Square Tests & Value & df & $\begin{array}{c}\text { Asymp. Sig. } \\
\text { (2-sided) }\end{array}$ \\
\hline $\begin{array}{c}\text { Pearson Chi- } \\
\text { Square }\end{array}$ & $25.703^{\mathrm{a}}$ & 60 & 1.000 \\
\hline Likelihood Ratio & 14.789 & 60 & 1.000 \\
\hline N of Valid Cases & 101 & & \\
\hline
\end{tabular}




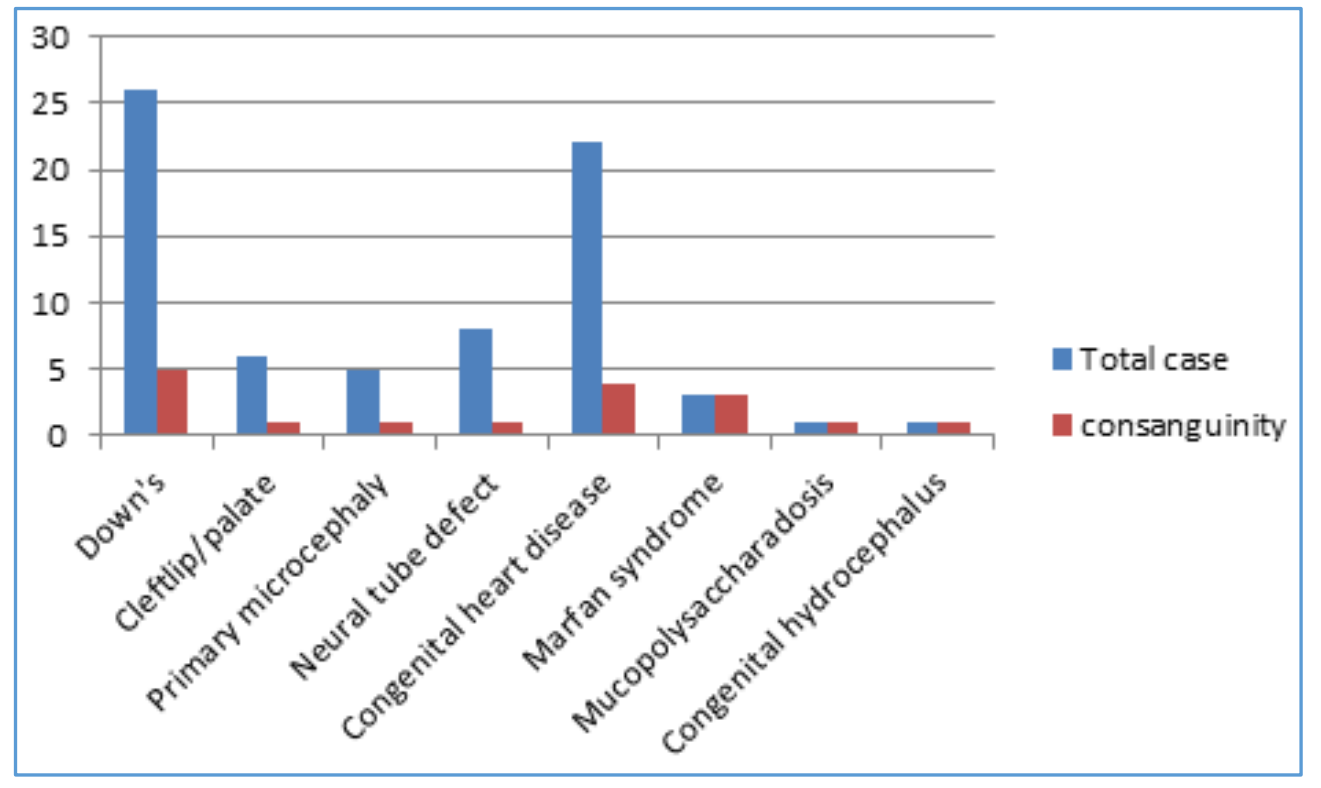

\begin{tabular}{|c|c|c|c|}
\hline $\begin{array}{c}\text { Chi-Square } \\
\text { Tests }\end{array}$ & Value & df & $\begin{array}{c}\text { Asymp. Sig. } \\
\text { (2-sided) }\end{array}$ \\
\hline $\begin{array}{c}\text { Pearson Chi- } \\
\text { Square }\end{array}$ & $8.6467 \mathrm{a}$ & 330 & .01 \\
\hline $\begin{array}{c}\text { Likelihood } \\
\text { Ratio }\end{array}$ & 4.2796 & 330 & .005 \\
\hline $\begin{array}{c}\text { No. of Valid } \\
\text { Cases }\end{array}$ & 100 & & \\
\hline
\end{tabular}

Correlation of Family History of Congenital Anomaly in Study Population

\begin{tabular}{|c|c|c|c|}
\hline Chi-Square Tests & Value & df & $\begin{array}{c}\text { Asymp. Sig. } \\
\text { (2-sided) }\end{array}$ \\
\hline Pearson Chi-Square & $86.615^{\mathrm{a}}$ & 80 & .287 \\
\hline Likelihood Ratio & 30.658 & 80 & 1.000 \\
\hline No. of Valid Cases & 100 & & \\
\hline
\end{tabular}

From the above table, we infer that the p-value is less than the level of significance (i.e. 0.05), so we accept our hypothesis, hence we concluded that consanguinity and congenital anomaly are associated.

Correlation of antenatal risk factors and congenital anomaly

\begin{tabular}{|c|c|c|c|}
\hline $\begin{array}{c}\text { Chi-Square } \\
\text { Tests }\end{array}$ & Value & df & $\begin{array}{c}\text { Asymp. Sig. } \\
\text { (2-sided) }\end{array}$ \\
\hline $\begin{array}{c}\text { Pearson Chi- } \\
\text { Square }\end{array}$ & $25.703^{\mathrm{a}}$ & 60 & 1.000 \\
\hline $\begin{array}{c}\text { Likelihood } \\
\text { Ratio }\end{array}$ & 14.789 & 60 & 1.000 \\
\hline
\end{tabular}
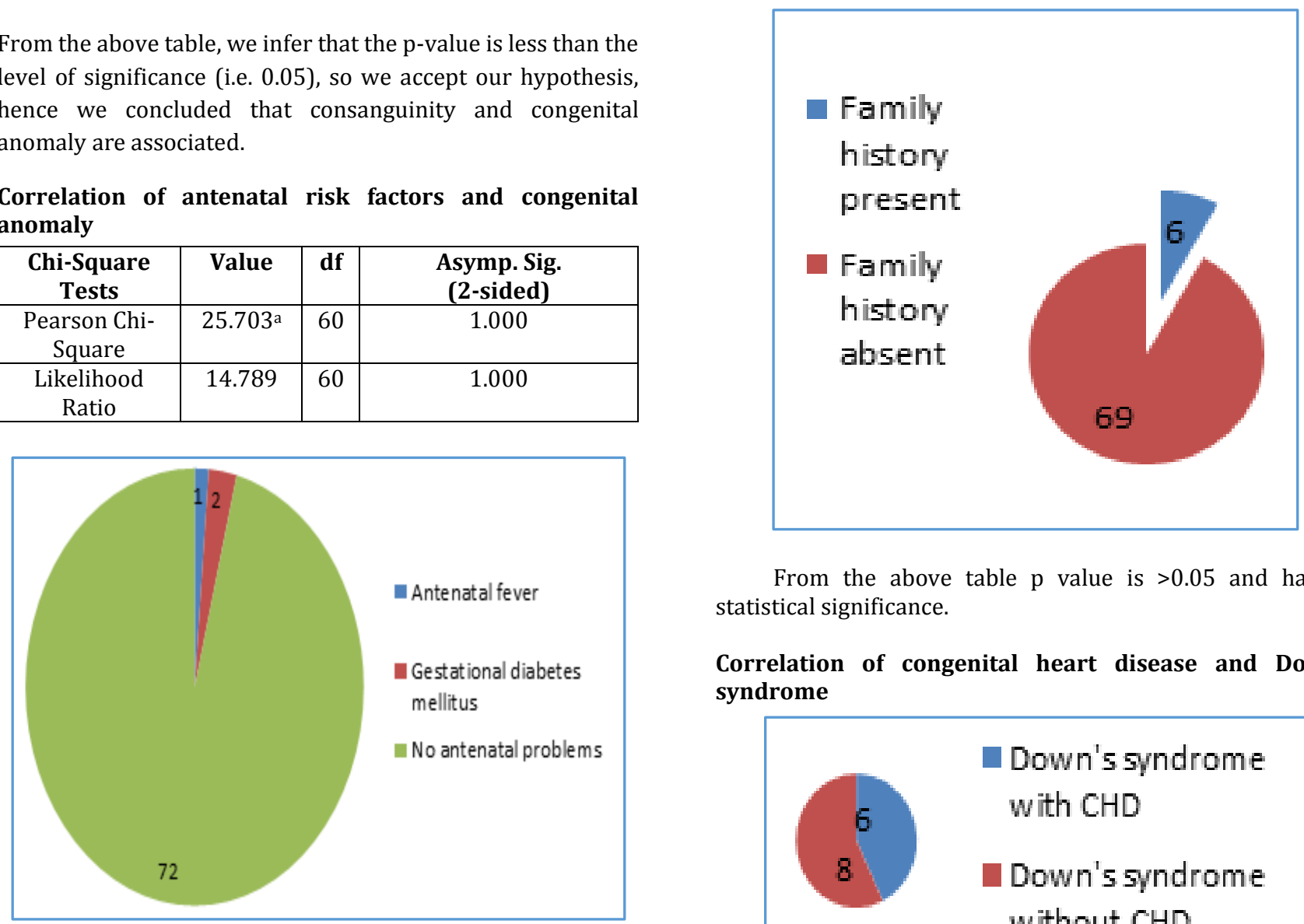

From the above table $\mathrm{p}$ value is $>0.05$ and has no statistical significance.

Correlation of congenital heart disease and Down's syndrome

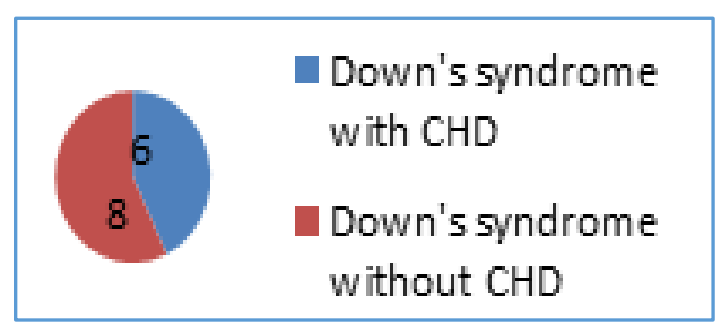

From the above table, we infer that the p-value is greater than the level of significance (i.e. 0.05), so we reject our hypothesis, hence we concluded that antenatal risk factors and congenital anomaly are not associated.

Congenital heart disease is present in $6(42 \%)$ cases of Down's syndrome with $\mathrm{p}$ value $<0.05$, which is statistically significa 


\section{DISCUSSION}

This study was conducted to identify the chromosomal imbalances in children and to correlate with multiple factors like maternal age, consanguinity, antenatal risk factors, family history were studied. Karyotyping is not routinely done in all congenital anomalous child. In this study, attempts were made to correlate the congenital anomaly with their chromosomal abnormalities; 75 children with major or minor congenital anomaly was included in this study. Relevant data like maternal age, paternal age, antenatal risk factors, consanguinity, family history were obtained from the parents/caregiver and entered in the proforma.

One child with features of Down's syndrome was from orphanage and so their parents and antenatal details could not be obtained. Chest x-ray, ultrasound abdomen, echocardiogram were done to the children. Then $3 \mathrm{ml}$ of blood was taken in the peripheral vein and subjected for karyotyping. Demographic features of the study population were analysed. Most of the children in this study (66.66\%) were less than 1 year of age.

In this study, 45 females and 30 males were included. Out of 45 females and 30 males with congenital anomalies, chromosomal abnormalities were detected in 13(28.88\%) and $5(16.66 \%)$ respectively. There is increase in chromosomal abnormalities in females were observed in this study. In the study done by Radhakrishnan Yashwanth et al. ${ }^{2}$ in Down's syndrome boys are having more chromosomal abnormalities than girls.

This is probably attributed to other factors, which plays the role. In this study, chromosomal abnormalities was identified in 18 out of 75 cases (24\%). The most common chromosomal abnormality identified was Down's syndrome (77.77\%). This was supported by a study done by Radhakrishnan Yashwanth et al. ${ }^{2}$ The other abnormalities identified are Turner's syndrome (5.55\%), Trisomy $19(5.55 \%)$, satellite $13(5.55 \%)$ and satellite $22(5.55 \%)$. Out of 14 Down's syndrome, Trisomy 21 was present in 12 cases $(85.71 \%)$ and mosaic pattern was seen in 2 cases $(14.28 \%)$.

Chromosome study in suspected of having Genetic Disorders has been done by various workers like Verma et al., Shah et al., Nkanza et al., Wahied Khawar Balwan. ${ }^{3}$ and Mohammad et al. ${ }^{4}$ in which they reported wide variations in the frequency of chromosomal abnormalities. In this study the chromosomal abnormalities detected was $24 \%$, which is higher than the national statistics. This can be due to the study done in tertiary centre with referred cases with full features of syndrome.

The most common chromosomal abnormality detected in this study was Down's syndrome, which was similar to the result shown by other workers. According to the literature, the mosaicism in Down's syndrome was 0-4\%, but in the present study it was higher $14.28 \%$. In the 18 reported cases, 1 case of trisomy 19 was identified which a rare case was presented with pointed chin, over riding of fingers and rocker bottom foot. Child had atrial septal defect in echocardiogram. Three cases only reported so far.

Ledbetter. $^{5} 1995$ reported a case of trisomy 19. In this study, 2 satellite chromosomes were identified which is the chromosome containing extra centromere. Satellite 13 was identified in a case of syndactyly with absent pectoralis major. Another case of satellite 22 was identified in a primary microcephaly case. On comparing the major and minor anomalies in this study, major anomalies comprise about $37 \%$ and minor anomalies comprise $62.6 \%$. This is supported by the study done by Queisser-Lufta et al. on malformations in newborn. ${ }^{6}$ which showed that minor anomalies are more prevalent than major anomalies.

Most common external anomalies detected is Down's features followed by central nervous system anomalies, limb anomalies, cleft lip/palate, Turner's features and Edward features respectively. In this study, the correlation of external anomaly and chromosomal abnormalities were statistically significant with $p$ value $<0.05$. In contrast, Akruti Parmar et al. done study in congenital anomalies in newborn which showed central nervous system anomalies are more common. Internal anomalies are present in 26 out of 75 children, which is $34.66 \%$.

Among the distribution of internal anomalies in study population congenital heart disease is the common anomaly (84.64\%), which is also common in Down's syndrome cases also. Other anomalies detected are tracheoesophageal fistula and renal anomalies. In this study, the correlation of internal anomaly and chromosomal abnormalities were statistically significant with $\mathrm{p}$ value $<0.05$. It is supported by the annual report of ICMR, study done by Amar Taksande, et al. Most common internal anomaly detected in Down's syndrome in this study was congenital heart disease (42\%).

Existing literature on Down's syndrome shows the prevalence of congenital heart disease in Down's syndrome is approximately $50 \% .^{7}$ Common congenital heart disease identified in this study was atrioventricular septal defect. In the present study, more mothers are coming in the age group of 20 to 25 years (64\%); $14.66 \%$ mothers were less than 20 years. The distribution of maternal age in congenital anomalies showed $\mathrm{p}$ value $>0.05$ and there is no statistical significance.

Regarding the Down's syndrome, mostly maternal age comes between 20 to 30 years (76.9\%). Most of the literature shows there is a linear correlation between increasing maternal age and Down's syndrome. This is attributed to the fact that most of our study mothers in study population was less than 30 years of age. In this study, consanguinity was identified in $17(22.66 \%)$ cases. This is statistically significant $(\mathrm{p}<0.05)$.

Various literatures also supported this. Alan H Bittles et al., Naeimeh Tayebi et al. done studies on consanguineous marriage and congenital anomaly, which showed that there is a positive correlation between consanguineous marriage and congenital anomalies. We studied the antenatal risk factors, family history of congenital anomaly which shows there is no statistical significance. Eight children died in the course of study. In the 8 children, only 2 children had chromosomal abnormality which is statistically not significant. One children died due to refractory cardiac failure and other child due to sepsis.

\section{SUMMARY}

Number of cases studied-

75.

1. Male -30 and female -

45.

2. Major anomalies -28 and Minor anomalies -47 .

\section{External Anomaly Distribution}

\begin{tabular}{|c|c|}
\hline Congenital Heart Disease & 22 \\
\hline Renal anomalies & 1 \\
\hline Tracheo-esophageal fistula & 2 \\
\hline Hypothyroidism & 1 \\
\hline
\end{tabular}

\begin{tabular}{|c|c|}
\hline Down's features & 26 \\
\hline Cleft lip/palate & 6 \\
\hline Primary microcephaly & 5 \\
\hline Neural tube defect & 8 \\
\hline Congenital heart disease & 22 \\
\hline Marfan syndrome & 3 \\
\hline Mucopolysaccharidosis & 1 \\
\hline Congenital hydrocephalus & 1 \\
\hline
\end{tabular}


Most common external anomaly identified was Down's features, 26 cases in which 14 cases had karyotypic positive for Down's syndrome. Internal anomalies distribution. Most common internal anomaly identified was congenital heart disease, which is also common in Down's syndrome cases also. Most common congenital heart disease in Down's syndrome was atrio-ventricular septal defect. Number of chromosomal abnormalities detected-18.

\section{Distribution of Chromosomal Abnormalities}

\begin{tabular}{|c|c|}
\hline Trisomy 21 & 12 \\
\hline Trisomy mosaic 21 & 2 \\
\hline $45+\mathrm{X} 0$ & 1 \\
\hline Trisomy 19 & 1 \\
\hline Satellite & 2 \\
\hline
\end{tabular}

\section{CONCLUSION}

- Since the proportion of Down's syndrome in this study is high, it recommends Down's screening in all antenatal mothers.

- Karyotyping is recommended for dysmorphic children.

- Congenital anomalies has significance with consanguineous marriage in this study, hence couples should be counseled and awareness should be created among public.

- Even though karyotyping identifies chromosomal abnormalities, it may still miss smaller chromosomal defects. Hence in strongly suspected cases, even if karyotyping is normal they should be subjected to improvised techniques like FISH.

\section{REFERENCES}

1. World Health Organisation report on congenital anomalies, www.who.int/topics/geneticanomalies/en/.

2. Radhakrishnan Yashwanth, Nallathambi Chandra and PM Gopinath. Chromosomal Abnormalities among Children with Congenital Malformations. Int J Hum Genet, 10(1-3):57-63(2010).

3. Wahied Khawar Balwan and Subash Gupta. Karyotypic Detection of chromosomal abnormalities in referred cases with suspected genetic disorders. Bull Env Pharmacol Life Sci Volume 2 [1] December 2012:16-19.

4. Yasir A Mohammed, Rabah M Shawky, Amal AS Soliman, et al. Chromosomal study in newborn infants with congenital anomalies in Assiut University Hospital, The Egyptian Journal of Medical Human Genetics, May 2011 vol 12, p-79-90.

5. Queisser-Luft A, Stolz G, Wiesel A, et al. Malformation in newborn 1990-1998, Arch Gynecol Obstet 2002 Jul 266(3);163-7.

6. Ledbetter DH, Engel E, 1995. Uniparental disomy in humans, development of imprinting map and its implication for prenatal diagnosis, oxford journals, vol 4 p-1757-1764.

7. Kliegman, Stanton, St Geme, et al. Text book of pediatrics, $20^{\text {th }}$ edition, cytogenetics, $\mathrm{p}-611$. 